\title{
Conversion of Aldoses to Valuable omega-Amino Alcohols Using Amine Transaminase Biocatalysts
}

\author{
Ryan Cairns, Andrew Gomm, ${ }^{\star}$ James Ryan, ${ }^{\ddagger}$ Thomas Clarke, Evelina Kulcinskaja, Kevin Butler, Elaine \\ O’Reilly*
}

School of Chemistry, University of Nottingham, University Park, Nottingham, NG7 2RD, United Kingdom

\begin{abstract}
The conversion of readily available monosaccharides to high-value amino alcohols using a key biocatalytic step is an attractive strategy for the preparation of these chiral synthons. Here, we report a previously undescribed example of the direct amination of monosaccharides, which exist predominantly in their cyclic form at equilibrium, using amine transaminase biocatalysts, providing access to a panel of amino alcohols in moderate to high conversion and isolated yield. A recently developed high-throughput colorimetric screen, employing $o$-xylylenediamine, was initially used to identify amine transaminase enzymes displaying this activity towards cyclic sugars and reactions were successfully scaled-up using isopropylamine.
\end{abstract}

KEYWORDS: amine transaminase, amino alcohol, biocatalysis, monosaccharide, sugar

The development of efficient biocatalytic routes for the synthesis of optically pure (agro)chemicals and pharmaceuticals that are difficult to access using more traditional synthetic methodology remains an important challenge and has inspired the concept of biocatalytic retrosynthesis. ${ }^{1}$ Of particular relevance, is the need to reduce our dependence on fossil fuel-derived chemicals and find alternative, low-cost and sustainable starting materials for the production of these molecules. ${ }^{2}$ The aldehyde and ketone functionality present in carbohydrates provides an opportunity to exploit this abundant feedstock for the production of valuable chiral amino alcohols/aminopolyols, via direct amination. These compounds represent valuable synthons for the generation of a diverse array of (chiral) molecules. ${ }^{3}$ However, achieving selectivity using traditional reductive amination is extremely challenging and typically requires the use of metals/metal-ligand complexes. ${ }^{4}$ Access to enzymes capable of installing an amino group and affording highly functionalized chiral templates that can be further decorated is an attractive prospect.

The application of amine transaminases (ATAs) for the conversion of aldehydes and pro-chiral ketones to the corresponding (chiral) amines in the presence of a pyridoxyl-5phosphate (PLP) coenzyme and suitable amine donor is well established. $^{5}$ However, the only report of ATA-mediated conversion of simple sugars to amino alcohols have been with the tetroses, D-erythrose and L-erythrulose (scheme 1 (i)), ${ }^{6}$ which do not readily form cyclic structures, and this transformation has not been reported for monosaccharides that cyclize to form hemiacetals. While the less studied sugar aminotransferases (SATs) play an important biosynthetic role in the amination of oxidised sugars (scheme 1 (ii)), this enzyme class is only active on sugar phosphates and sugar nucleotides and activity on simple monosaccharides has not yet been reported. ${ }^{7}$ The absence of literature reporting transaminase activity on simple monosaccharides suggests that they have simply been overlooked as potential substrates.
Biocatalysis has been successfully employed for the synthesis of valuable amino alcohols starting from simple building blocks by designing multi-enzyme cascades. $^{6 \mathrm{~b}, 8}$ However, there is enormous scope for the development of a one-step strategy via direct amination from simple and easily accessable monosaccharides (scheme 1 (iii)). Here, we report the direct biocatalytic amination of aldoses, which exist as cyclic sugars in equilibrium. The strategy, which exploits transaminases, allows access to a range of chiral omega-amino alcohols on a preparative-scale, starting from the corresponding aldoses.

Scheme 1. Biocatalytic Strategies for the Direct Amination of Sugars.

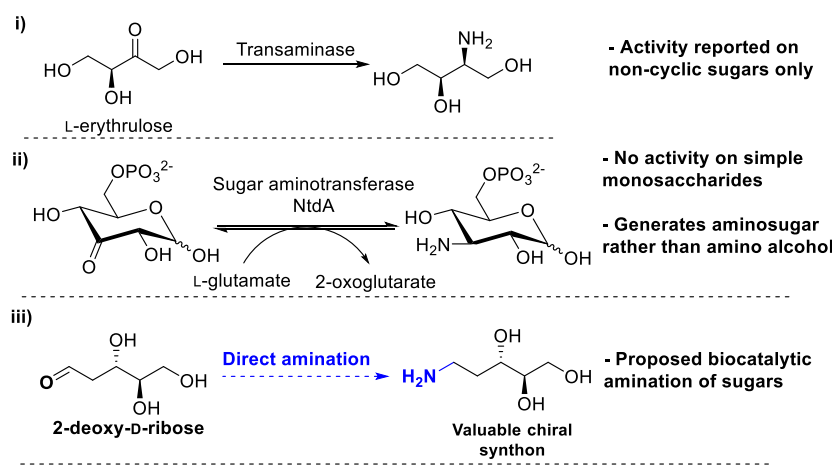

i) Amination of the non-cyclic sugar L-erythrulose ${ }^{6}$ and ii) sugar phosphates $^{7 \mathrm{a}}$ using transaminase enzymes. iii) Proposed strategy for the direct amination of aldoses that exist predominantly as cyclic structures, using amine transaminase biocatalysts, affording valuable amino alcohols.

We initially evaluated the ability of four commercially available ATAs to convert selected monosaccharides to the cor- 
responding amino alcohols, using our previously reported $o$-xylylenediamine colorimetric screen ${ }^{9}$ (figure 1). Application of commercially available $o$-xylylenediamine as the amine donor leads to the formation of an isoindole co-product that rapidly polymerizes, resulting in a colored polymer and providing a convenient method for identifying ATA activity. The acceptor panel screened comprised 15 sugars that were commercially available and of relatively low-cost. The liquid-phase assay revealed that a number of the sugars showed some activity with one or more of the ATAs. Of the four commercially available enzymes screened, $(S)$-selective ATA $256^{10}$ displayed the best activity towards the sugar panel and was selected for further evaluation. Six wild-type (WT) ATAs were also evaluated against a similar sugar panel (see supporting information for more information and assay details). The WT ATAs that showed the highest activity on the panel of sugars were a putrescine transaminase, HEWT, from Halomonas elongata (DSM 2581) $)^{6 \mathrm{a}}$ and 3HMU from Rugeria pomeroy (DSM 15171). ${ }^{11}$

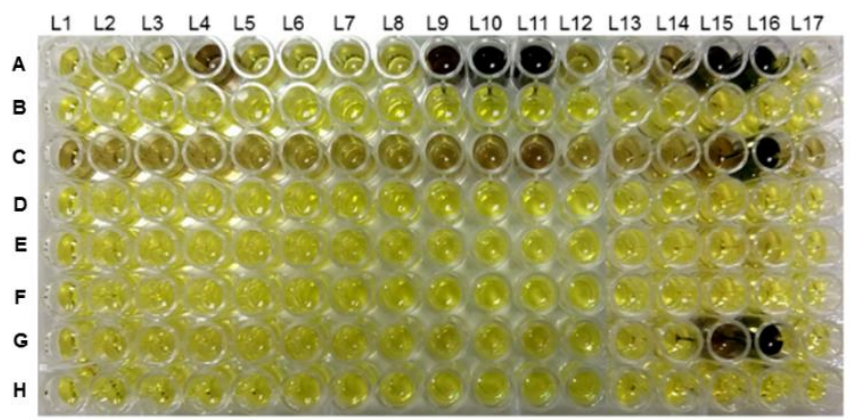

Figure 1. $O$-Xylylenediamine colorimetric screen used to identify sugar substrates. Enzymes: Row A: ATA256 Row C: ATA113; Row E: ATA025; Row G: ATA117. Rows B, D, F and $\mathbf{H}$ are control reactions containing no enzyme. L1: D-glucose; L2: D-mannose; L3: D-galactose; L4: 2-deoxy-D-galactose; L5: L-rhamnose; L6: tagatose; L7: D-fructose; L8: L-sorbose; L9: D-ribose; L10: 2deoxy-D-ribose; L11: 2-deoxy-L-ribose; L12: D-arabinose; L13: D-lyxose; L14: D-erythrose; L15: L-erythrulose; L16: pyruvate; L17: no acceptor. Dark wells indicate activity. Enzyme (0.1 $\mathrm{mg} / \mathrm{mL})$ was added to a mixture of $o$-xylylenediamine $(5 \mathrm{mM})$, sugar $(5 \mathrm{mM})$ and PLP $(0.1 \mathrm{mM})$ in HEPES buffer $(200 \mu 1,100$ $\mathrm{mM}, \mathrm{pH} 8.0)$.

Analytical-scale biotransformations were first carried out with ATA256, HEWT and 3HMU and a single sugar substrate, 2-deoxy-D-ribose, to establish the optimum conditions for performing these reactions. A range of $\mathrm{pH}$ values, temperatures and amine donors/amine donor concentrations were evaluated (see supporting information). ATA256 performed well over a broad $\mathrm{pH}$ range as did HEWT. WT 3HMU appeared to be more sensitive to changes in $\mathrm{pH}$. All enzymes were screened at $30{ }^{\circ} \mathrm{C}$ and $50{ }^{\circ} \mathrm{C}$ and as expected, commercial variant ATA256 performed better at the higher temperature, while the activity of the WT enzymes was significantly decreased at $50{ }^{\circ} \mathrm{C}$. A screen of the amine donors revealed that 1-3 equivalents of $o$-xylylenediamine or IPA were effective at displacing the reaction equilibrium and enabling good conversion of 2-deoxy-D-ribose to the corresponding amino alcohol, with one or more of the ATAs. Based on this data, suitable conditions were selected for each enzyme and reactions performed on an expanded sugar panel (Figure 2).

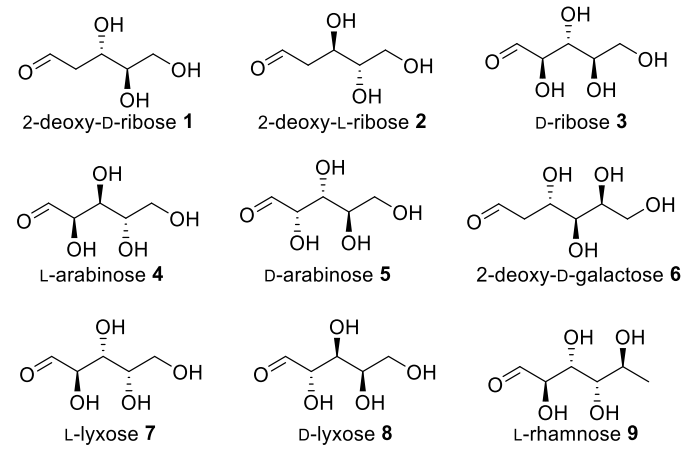

Figure 2. Sugar substrates 1-9 selected for analytic-scale biotransformations following initial colorimetric assay.

Biotransformations with substrates 1-9 $(10 \mathrm{mM})$ were carried out using 1.1 equivalents of $o$-xylylenediamine (table 1 ) and reactions evaluated by NMR. To accurately establish the percentage conversion, maleic acid was added to the NMR samples as an internal standard and the formation of the product protons, $\mathrm{H}_{\mathrm{B}}$, were monitored (figure 3 , see supporting information for details). Despite the low concentration of the openchain sugar substrate available at equilibrium (typically less than $1 \%$ ), conversions of up to $69 \%$ were achieved using just 1.1 equivalents of the amine donor, $o$-xylylenediamine. All three enzymes performed better with deoxy-sugars 1,2 and 6 and generally displayed lower activity towards the non-deoxy derivatives. While it would be interesting to explore the relationship between the concentration of active carbonyl species in solution and the overall conversion achieved, there appears to be no obvious correlation between the two, based on values for the mutarotation rates reported in the literature. ${ }^{12}$ Measuring these concentrations accurately is challenging due to the low concentration of the species and this was not explored in detail in this study. No stereochemistry preference pattern emerged from this screen, although a larger panel of sugars would need to be evaluated to draw meaningful conclusions.

Table 1. The Conversion of Monosaccharides 1-9 to the Corresponding Amino Alcohols. ${ }^{a}$

\begin{tabular}{llll}
\hline Substrate & $\begin{array}{l}\text { Conv. } \\
\text { ATA256 }\end{array}$ & $\begin{array}{l}\text { Conv. } \\
\text { 3HMU }\end{array}$ & $\begin{array}{l}\text { Conv. } \\
\text { HEWT }\end{array}$ \\
\hline 2-deoxy-D-ribose $\mathbf{1}$ & 68 & 51 & 66 \\
2-deoxy-L-ribose $\mathbf{2}$ & 39 & 35 & 69 \\
D-ribose 3 & 22 & 17 & 41 \\
L-arabinose $\mathbf{4}$ & 3 & 6 & 8 \\
D-arabinose $\mathbf{5}$ & 7 & 3 & 3 \\
2-deoxy-D-galactose $\mathbf{6}$ & 14 & 15 & 35 \\
L-lyxose 7 & 11 & 13 & 6 \\
D-lyxose 8 & 7 & 2 & 5 \\
L-rhamnose 9 & 10 & 2 & 25 \\
\hline
\end{tabular}

a1.1 equivalents of $o$-xylylenediamine was employed with $10 \mathrm{mM}$ sugar substrate. Conversions were calculated by NMR. All reactions were performed in triplicate. See supporting information for reaction conditions. 'Substrate was not included in the initial colorimetric screen. 


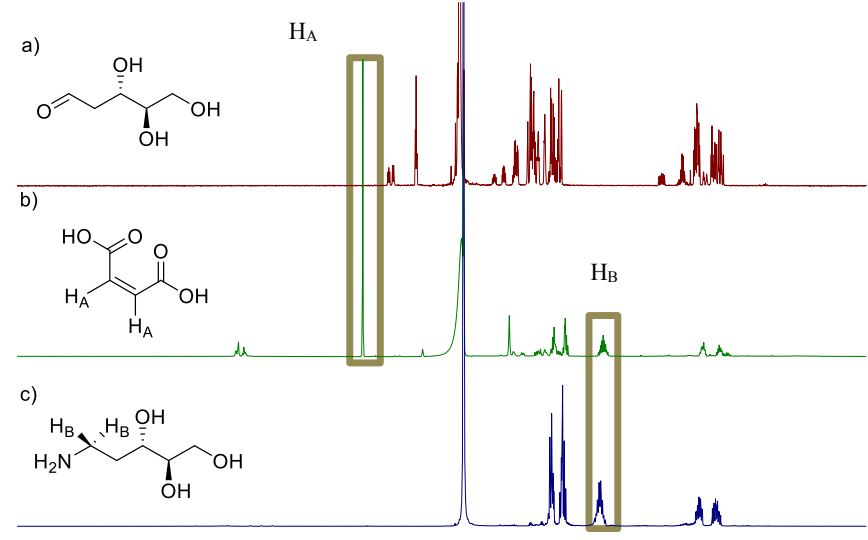

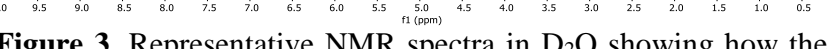
conversion of 2-deoxy-D-ribose is monitored (see supporting information for further details). (a) 2-deoxy-D-ribose; (b) biotransformation of 2-deoxy-D-ribose with ATA256 after 24 hours. The reaction is spiked with maleic acid and shows the formation of the amino alcohol product, $(2 R, 3 S)$-5-aminopentane1,2,3-triol; (c) synthetic standard of (2R,3S)-5-aminopentane-1,2,3triol.

Commercially available ATA256 was selected for the preparative-scale synthesis of nine amino alcohols 10-18 (see supporting information for amino alcohol structures), employing $100 \mathrm{mM}$ or $200 \mathrm{mM}$ of the starting sugar. As initial analytical results showed that just 3 equivalents of IPA was sufficient to achieve an $83 \%$ conversion of 2-deoxy-D-ribose to the corresponding amino alcohol (data not shown), this amine donor was selected to perform the preparative-scale biotransformations. Excellent conversions to the corresponding amino alcohols 1018 could be achieved for a number of the substrates, using 4 equivalents of IPA and either $100 \mathrm{mM}$ or $200 \mathrm{mM}$ of the sugar substrate at $50{ }^{\circ} \mathrm{C}$. Products were isolated in moderate-good yields (table 2) enabling up to $475 \mathrm{mg}$ of amino alcohol to be isolated. The results clearly demonstrate the suitability of this methodology for the scalable biocatalytic synthesis of these valuable products.

Table 2. Preparative-Scale Synthesis of Selected Amino Alcohols. $^{a}$

\begin{tabular}{llllll}
\hline Substrate & $\begin{array}{l}\text { Amino } \\
\text { alcohol }\end{array}$ & $\begin{array}{l}\text { Conc. } \\
\mathrm{mM}\end{array}$ & $\begin{array}{l}\text { Conv. } \\
\%\end{array}$ & $\begin{array}{l}\text { Yield } \\
\%\end{array}$ & $\begin{array}{l}\text { Isolated } \\
\mathrm{mg}\end{array}$ \\
\hline 2-deoxy-D-ribose $\mathbf{1}$ & $\mathbf{1 0}^{\mathbf{b}}$ & 200 & 94 & 69 & 475 \\
2-deoxy-L-ribose 2 & $\mathbf{1 1}^{\mathbf{b}}$ & 200 & 94 & 69 & 474 \\
D-ribose 3 & $\mathbf{1 2}^{\mathbf{b}}$ & 100 & 62 & 47 & 176 \\
L-arabinose 4 & $\mathbf{1 3}^{\mathbf{b}}$ & 100 & 35 & 28 & 104 \\
D-arabinose 5 & $\mathbf{1 4}^{\mathbf{b}}$ & 100 & 75 & 38 & 144 \\
2-deoxy-D-galactose $\mathbf{6}$ & $\mathbf{1 5}^{\mathbf{b}}$ & 100 & 30 & 22 & 88 \\
L-lyxose 7 & $\mathbf{1 6}^{\mathbf{b}}$ & 200 & 24 & $16^{\mathrm{c}}$ & 121 \\
D-lyxose 8 & $\mathbf{1 7}^{\mathbf{b}}$ & 200 & 21 & $11^{\mathrm{c}}$ & 86 \\
L-rhamnose 9 & $\mathbf{1 8}^{\mathbf{b}}$ & 100 & 48 & 33 & 131 \\
\hline
\end{tabular}

${ }^{\mathrm{a} C o m m e r c i a l l y ~ a v a i l a b l e}(S)$-selective ATA256 and 4 equivalents of IPA was employed with either $100 \mathrm{mM}$ or $200 \mathrm{mM}$ of sugar substrate. Conversions were calculated by NMR after 48 hours and isolated yields are reported after purification on Dowex resin. See supporting information for reaction conditions, compound characterisation and ${ }^{b}$ product structures. ${ }^{c}$ After purification, compounds are still contaminated with IPA. $\mathrm{HCl}$ salt.

In summary, we have demonstrated the first example of the biocatalytic conversion of simple, cyclic sugars to the corresponding amino alcohols using amine transaminase enzymes. Having initially identified promising sugar substrates using a colorimetric assay employing $o$-xylylenediamine and subsequently performing analytical-scale reactions, a selection of amino alcohols were synthesised on a preparative-scale using a commercially available amine transaminase. This methodology allowed easy access to large quantities of amino alcohol product and has the potential to become the go-to approach for the synthesis of amino alcohols from simple monosaccharides. Efforts are currently focused on the identification of transaminase biocatalysts that accept a broader range of monosaccharides, including ketoses.

\section{ASSOCIATED CONTENT}

Supporting Information. This material is available free of charge via the Internet at http://pubs.acs.org and contains synthetic procedures, procedures for gene expression and protein purification, a description of analytical and preparative-scale biotransformations, assay procedures and detailed compound characterization, including NMR data and spectra.

\section{AUTHOR INFORMATION}

\section{Corresponding Author}

*E-mail: elaine.oreilly@nottingham.ac.uk

$\$$ These authors contributed equally.

\section{Notes}

The authors declare no competing financial interest.

\section{ACKNOWLEDGMENT}

Research leading to these results has received funding from the BBSRC (BB/M021947/1), the BBSRC Doctoral Training Programme BBSRC DTP (UK) [grant number BB/M008770/1], the EPSRC Centre for Doctoral Training in Sustainable Chemistry (grant number EP/L015633/1) and the University of Nottingham. The UK Catalysis Hub is kindly thanked for resources and support provided via our membership of the UK Catalysis Hub Consortium and funded by EPSRC (grants EP/K014706/2, EP/K014668/1, EP/K014854/1, EP/K0147 14/1 and EP/M013219/1). We are grateful to Dr Francesca Paradisi and Prof. Uwe Bornscheuer for supplying plasmid DNA for the non-commercial enzymes used in this study.

\section{REFERENCES}

(1) a) Turner, N. J.; O'Reilly, E. Biocatalytic Retrosynthesis. Nat. Chem. Biol. 2013, 9, 285-288;

b) de Souza, R. O. M. A.; Miranda, L. S. M.; Bornscheuer, U. T. A Retrosynthesis Approach for Biocatalysis in Organic Synthesis. Chem. Eur. J. 2017, 23, 12040-12063; c) Hönig, M.; Sondermann, P.; Turner, N. J.; Carreira, E. M. Enantioselective Chemo- and Biocatalysis: Partners in Retrosynthesis. Angew. Chem. Int. Ed. 2017, 56, 8942-8973; d) Green, A. P.; Turner, N. J. Biocatalytic Retrosynthesis: Redesigning Synthetic Routes to High-Value Chemicals. Perspect. Sci. 2016, 9, 42 48.

(2) Cherubini, F. The Biorefinery Concept: Using Biomass Instead of Oil for Producing Energy and Chemicals. Energy Conversion and Management. Energy Convers. Manag. 2010, 51, 1412-1421. 
(3) a) Tamura, M.; Tamura, R.; Takeda, Y.; Nakagawa, Y.; Tomishige, K. Catalytic Hydrogenation of Amino Acids to Amino Alcohols with Complete Retention of Configuration. Chem. Commun. 2014, 50, 6656-6659; b) Srimani, D.; Ben-David, Y.; Milstein, D. Direct Synthesis of Pyrroles by Dehydrogenative Coupling of $\beta$ Aminoalcohols with Secondary Alcohols Catalyzed by Ruthenium Pincer Complexes. Angew. Chem. Int. Ed. 2013, 52, 4012-4015; c) Ramasastry, S. S. V.; Zhang, H.; Tanaka, F.; Barbas, C. F. Direct Catalytic Asymmetric Synthesis of anti-1,2-Amino Alcohols and syn1,2-Diols through Organocatalytic anti-Mannich and syn-Aldol Reactions. „J. Am. Chem. Soc. 2007, 129, 288-289; d) Shi, S. -L.; Wong, Z. L.; Buchwald, S. L. Copper-Catalysed Enantioselective Stereodivergent Synthesis of Amino Alcohols. Nature, 2016, 532, 353356.

(4) Baxter, E. W.; Reitz, A. B. Organic Reactions, Vol. 59, (Eds.: Overman, L. E.) John Wiley \& Sons, Inc., 2001.

(5) a) Gomm, A.; O'Reilly, E. Transaminases for Chiral Amine Synthesis. Curr. Opin. Chem. Biol. 2018, 43, 106-112.; b) Guo, F.; Berglund, P. Transaminase Biocatalysts: Optimization and Application. Green Chem, 2017, 19, 333-360; c) Slabu, I.; Galman, J. L.; Lloyd, R. C.; Turner, N. J. Discovery, Engineering and Synthetic Application of Transaminase Biocatalysts. ACS Catal. 2017, 7, 82638284.

(6) a) Cerioli, L.; Planchestainer, M.; Cassidy, J.; Tessaro, D.; Paradisi, F. Characterization of a Novel Amine Transaminase from Halomonas Elongata. J. Mol. Cat: B. Enz. 2015, 120, 141-150; b) Ingram, C. U.; Bommer, M.; Smith, M. E. B.; Dalby, P. A.; Ward, J. M.; Hailes, H. C.; Lye, G. J. One-Pot Synthesis of Amino-Alcohols Using a De-Novo Transketolase and $\beta$-Alanine: Pyruvate Transaminase Pathway in Escherichia coli. Biotechnol. Bioeng. 2007, 96, 559-569; c) Smith, M. E. B.; Chen, B. H.; Hibbert, E. G.; Kaulmann, U.; Smithies, K.; Galman, J. L.; Baganz, F.; Dalby, P. A.; Hailes, H. C.; Lye, G. J.; Ward, J. M.; Woodley, J. M.; Micheletti, M. A Multidisciplinary Approach Toward the Rapid and Preparative-Scale Biocatalytic Synthesis of Chiral Amino Alcohols: A Concise Transketolase- $/ \omega$-TransaminaseMediated Synthesis of (2S,3S)-2-Aminopentane-1,3-diol. Org. Process Res. Dev. 2010, 14, 99-107.

(7) a) Vetter, N. D.; Langill, D. M.; Anjum, S.; Boisvert-Martel, J.; Jagdhane, R. C.; Omene, E.; Zheng, H.; van Straaten, K. E.; Asiamah, I.; Krol, E. S.; Sanders, D. A. R.; Palmer, D. R. J. A Previously Unrecognized Kanosamine Biosynthesis Pathway in Bacillus subtilis. J. Am. Chem. Soc. 2013, 135, 5970-5973; b) Singh, S.; Kim, Y.; Wang, F.;
Bigelow, L.; Endres, M.; Kharel, M. K.; Babnigg, G.; Bingman, C. A.; Joachimiak, A.; Thorson, J. S.; Phillips Jr., G. N. Structural Characterization of AtmS13, a Putative Sugar Aminotransferase Involved in Indolocarbazole AT2433 Aminopentose Biosynthesis. Proteins: Struct., Funct., Bioinf. 2015, 83, 1547-1554; c) Hwang, B. -Y.; Lee, H. -J.; Yang, Y. -H.; Joo, H. -S.; Kim, B. -G. Characterization and Investigation of Substrate Specificity of the Sugar Aminotransferase WecE from E. coli K12. Chem. Biol. 2004, 11, 915-925.

(8) Villegas-Torres, M. F.; Martinez-Torres, R. J.; Cázares-Körner, A.; Hailes, H.; Baganz, F.; Ward, J. Multi-Step Biocatalytic Strategies for Chiral Amino Alcohol Synthesis. Enzyme Microb. Technol. 2015, 81, 23-30.

(9) Green, A. P.; Turner, N. J.; O'Reilly, E. Chiral Amine Synthesis Using $\omega$-Transaminases: An Amine Donor that Displaces Equilibria and Enables High-Throughput Screening. Angew. Chem. Int. Ed. 2014, 53, 10714-10717.

(10) The sequence for ATA256 can be found in the following patent. Crowe, M.; Foulkes, M.; Francese, G.; Grimler, D.; Kuesters, E.; Laumen, K.; Li, Y.; Lin, C.; Nazor, J.; Ruch, T.; Smith, D.; Song, S.; Teng, S. Chemical Processes for Preparing Spiroindolones and Intermediates Thereof. US Patent US 2015/0045562 A1, filed 22 March 2013 and issued 12 February 2015.

(11) Steffen-Munsberg, F.; Vickers, C.; Thontowi, A.; Schätzle, S.; Tumlirsch, T.; Humble, M. S.; Land, H.; Berglund, P.; Bornscheuer, U. T.; Höhne, M. Connecting Unexplored Protein Crystal Structures to Enzymatic Function. ChemCatChem. 2013, 5, 150-153.

(12) a) Pigman, W.; Isbell, H. S. Mutarotation of Sugars in Solution: Part I: History, Basic Kinetics and Composition of Sugar Solutions. Avd. Carbohydr. Chem. 1968, 23, 11-57; b) Cortes, S. J.; Mega, T. L.; Van Etten, R. L. The ${ }^{18} 0$ Isotope Shift in ${ }^{13} \mathrm{C}$ Nuclear Magnetic Resonance Spectroscopy. Kinetics of Oxygen Exchange at the Anomeric Carbon of D-Ribose and D-2-Deoxyribose. J. Org. Chem., 1991, 56, 943-947. 


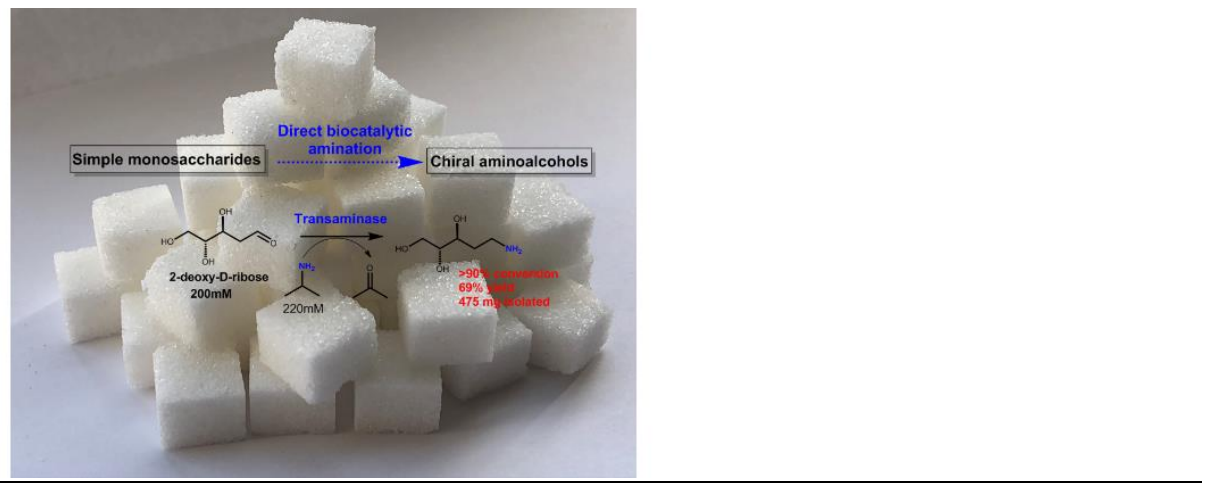

